\title{
Centrosome - a promising anti-cancer target
}

This article was published in the following Dove Press journal:

Biologics:Targets and Therapy

13 December 2016

Number of times this article has been viewed

\section{Yainyrette Rivera-Rivera Harold I Saavedra}

Department of Pharmacology, Ponce Health Sciences University-School of Medicine, Ponce Research Institute, Ponce, Puerto Rico
Correspondence: Harold I Saavedra Department of Pharmacology, Ponce Research Institute, Ponce Health Sciences University-School of Medicine, 395 Research Building Zona Industrial Reparada 2, Ponce 00716-

2348, Puerto Rico

Tel +I 7878402575

Fax +I $78784 \mid 5150$

Email hsaavedra@psm.edu
Abstract: The centrosome, an organelle discovered $>100$ years ago, is the main microtubuleorganizing center in mammalian organisms. The centrosome is composed of a pair of centrioles surrounded by the pericentriolar material (PMC) and plays a major role in the regulation of cell cycle transitions (G1-S, G2-M, and metaphase-anaphase), ensuring the normality of cell division. Hundreds of proteins found in the centrosome exert a variety of roles, including microtubule dynamics, nucleation, and kinetochore-microtubule attachments that allow correct chromosome alignment and segregation. Errors in these processes lead to structural (shape, size, number, position, and composition), functional (abnormal microtubule nucleation and disorganized spindles), and numerical (centrosome amplification [CA]) centrosome aberrations causing aneuploidy and genomic instability. Compelling data demonstrate that centrosomes are implicated in cancer, because there are important oncogenic and tumor suppressor proteins that are localized in this organelle and drive centrosome aberrations. Centrosome defects have been found in pre-neoplasias and tumors from breast, ovaries, prostate, head and neck, lung, liver, and bladder among many others. Several drugs/compounds against centrosomal proteins have shown promising results. Other drugs have higher toxicity with modest or no benefits, and there are more recently developed agents being tested in clinical trials. All of this emerging evidence suggests that targeting centrosome aberrations may be a future avenue for therapeutic intervention in cancer research.

Keywords: centrosomes, cell cycle, mitosis, CA, CIN, cancer therapy

\section{Introduction to the centrosome and its essential role in the cell cycle}

The centrosome is a small cytoplasmic organelle discovered by Edouard van Beneden, and further named and described by Boveri in the late 19th century. ${ }^{1}$ The centrosome is considered the principal microtubule-organizing center (MTOC) in mammalian cells; its core is composed of a pair of orthogonally localized centrioles embedded in a complex, dense protein matrix known as the pericentriolar material (PCM). ${ }^{2}$ Centrioles are diminutive barrel-shaped organelles $(0.5 \mu \mathrm{m} \text { in length and } 0.2 \mu \mathrm{m} \text { in diameter })^{3,4}$ organized in a cylindrical arrangement of nine triplet microtubules. ${ }^{5}$ The older centriole, also referred to as the "mother" centriole, duplicates to form a new centriole, known as the "daughter" centriole. The mother centriole has distal and sub-distal appendages that the daughter centriole lacks and functions mainly in the anchoring of new microtubules. ${ }^{6}$ The daughter centriole eventually matures and transforms into a mother centriole. ${ }^{7}$ In animal cells the centrioles form a cilium in dormant cells, while cells 
actively cycling form a centrosome. In some invertebrate species, such as the fruit fly Drosophila melanogaster, cilia are essential for mechano- and chemo-sensing, and flies lacking centrioles cannot form cilia and eventually die since they are unable to feed. ${ }^{8}$ Another example is the flatworm Schmidtea mediterranea, which does not regenerate through centrosomes and forms thousands of cilia for motility through the assembly of many centrioles. ${ }^{9}$ In humans, ciliopathies including primary ciliary dyskinesia, autosomal recessive primary microcephaly, polycystic kidney disease, and Bardet-Biedl disease are linked to defects caused by mutations in genes that encode centrosomal proteins. ${ }^{10}$

Centrosomes are formed when centrioles assemble and the PCM forms around centrioles. The PCM changes during the mitotic phase by increasing the inner layer and recruiting other components; this process culminates in a mature centrosome with optimal MTOC capacity. ${ }^{11}$ The PCM is composed of hundreds of proteins, ${ }^{12,13}$ including $\gamma$-tubulin ring complexes ( $\gamma$ TuRCs), highly organized into different spatial compartments; $; 1,14$ some of them function as signal molecules in the organization and nucleation of microtubules, ${ }^{15}$ anchoring, and regulation of the cell cycle. This section of the review will focus on the roles that centrosomes play during the cell cycle.

The first evidence shows that centrosomes and the microtubules they nucleate play roles in coordinating timing of mitosis and the cell cycle and that centrosome duplication which occurred in specific phases of the cell cycle was discovered by Sluder in sea urchin eggs. ${ }^{16}$ During the cell cycle or cell division, centrosomes change morphologically and functionally. ${ }^{17}$ Their duplication is coordinated with the cell cycle and also is coupled to DNA replication, mitosis, and cytokinesis through regulated pathways. ${ }^{18}$ Specifically, centrosomes regulate cell cycle transitions during G1 to S-phase (G1-S), G2 to M-phase (G2-M), and also from metaphase to anaphase (M-A) of the M-phase.

After cytokinesis a single centrosome starts to duplicate during the G1-S transition, finishing duplication at the S phase. ${ }^{19}$ Its duplication consists of the dissociation of the two preexisting centrioles to form a single procentriole proximal to the mother centriole. ${ }^{20}$ The existence of only two centrosomes before entering mitosis facilitates bipolar spindle formation and organization, and equal chromosomal division to each daughter cell. ${ }^{3}$ Microsurgery experiments using BSC-1 African green monkey kidney cells, where centrosomes on either interphase or in prophase were extirpated, led to failure of cells to enter into the next S-phase; these experiments demonstrated that centrosomes are needed to enter into the $\mathrm{S}$ phase of the cell cycle. Later it was demonstrated that this event is mediated by the formation of a complex of cyclin-dependent kinase 2 (Cdk2) with cyclin E and cyclin A complexes that are necessary for progression through the $\mathrm{S}$ phase. Now it is known that many cell cycle regulator proteins are involved in the regulation of centrosome duplication at late $\mathrm{G} 1$ and $\mathrm{S}$ phases and they mediate centrosome amplification (CA), including cyclin E, Cdk2, Cdk4, nucleophosmin (NPM) - a phosphorylation target of Cdk2 and Cdk4, as well as the E2F transcription factors. ${ }^{21-31}$ This subject has been thoroughly reviewed by several groups, including ours. . $^{1920,32}$ Other important proteins that are specific to the regulation of the centrosome cycle include polo like kinase 4 (Plk4) and monopolar spindle 1 kinase (Mps-1) and many reviews have discussed those proteins thoroughly. ${ }^{33-35}$ The Doxsey lab demonstrated using small interfering ribonucleic acids against several centrosome proteins that cells can also arrest at G1-S due to p53 (tumor suppressor protein), p21, and p38-dependent checkpoints activation. ${ }^{36}$

Previous studies demonstrated the role of centrosomes in the G2-M transition of the cell cycle, by purifying human centrosomes and microinjecting them into starfish oocytes arrested in the G2 phase, leading to the formation of some normal embryos, demonstrating that centrosomes support the progression from $\mathrm{G} 2$ to mitosis. ${ }^{37}$ Further, it was established that activation of $\mathrm{Cdk} 1 /$ cyclin $\mathrm{B}(\mathrm{Cdk} 1-\mathrm{CycB})$ is necessary to mitotic entry, ${ }^{38}$ and recruitment and activation of this complex is mediated through Aurora A kinase (AURKA). ${ }^{39}$ Also, centrosome localization of Cdk1 and inhibition of checkpoint kinase 1 (Chk1), which inhibits Cdk1 activity, exists in cells during mitosis. ${ }^{40}$ Centrosome localization of Plk1 is also another key step for the centrosome to exert its function to entry to mitosis. Plk1 regulates centrosome maturation ${ }^{41}$ centrosome disjunction by regulating never in mitosis gene A (NIMA)-related kinase 2 (Nek2)/protein phosphatase 1-gamma antagonism, ${ }^{42}$ and centrosome-microtubule attachments..$^{43}$ Thus, regulatory proteins recruited within the centrosome at the G2-M transition suggest an important role of centrosomes in mitosis.

Once the cell is in the mitotic phase, specifically at prophase, the two centrosomes migrate to the opposite poles of the cell and the mitotic spindle forms between centrosomes, facilitating cell division. ${ }^{44}$ At this point, the spindle assembly checkpoint (SAC) ensures the kinetochores attachment of chromosomes to spindle microtubules for faithful chromosomal segregation. Activation of the anaphase-promoting complex or cyclosome is required for the proper degradation of $\mathrm{CycB}$ and inactivation of $\mathrm{Cdk} 1-\mathrm{CycB}$ and changing the microtubule dynamics to exit mitosis. ${ }^{45}$ 
As centrosomes contain hundreds of proteins with different biological functions, it is not surprising that this cellular component is involved in regulating many processes, including microtubule dynamics.

\section{Centrosome-associated proteins that regulate microtubule dynamics and the spindle assembly checkpoint}

The centrosome plays an important role as the main MTOC in mammalian cells. The fidelity of a dynamic spindle is critical for proper alignment of chromosomes and faithful segregation of sister chromatids. Functional changes in microtubule/ spindle mechanisms commonly give rise to disturbances in the dynamics and abnormal structures, which in turn leads to increases in segregation errors and consequently aneuploidy ${ }^{46,47}$ The centrosome contains a significant number of proteins that are associated with the regulation of microtubule dynamics and the SAC, and we will briefly discuss some of them in this section.

The presence of alpha tubulin ( $\alpha$-tubulin), which is contained in the $\gamma \mathrm{TuRC}$, strengthens the structure of the centrosome in part by interacting with the centrosomal protein pericentrin. ${ }^{48}$ The Oakley group discovered $\gamma$-tubulin in Aspergillus nidulans and demonstrated that it influenced microtubule dynamics by binding $\gamma$-tubulin. ${ }^{49} \gamma$-Tubulin is conserved throughout evolution, its gene highly conserved in Xenopus laevis, Schizosaccharomyces pombe, maize, diatom, and budding yeast, ${ }^{50}$ and it is also present in centrosomes of human and drosophila cells. ${ }^{51}$ An in vitro system from Xenopus egg extracts demonstrated that $\gamma$-tubulin and adenosine triphosphate help assemble centrosomes and that the complex assembles around centrioles of the sperm and binds microtubules. ${ }^{52}$

The centrosome protein pericentrin is required for spindle microtubule nucleation during the mitotic phase. Experimental depletion of pericentrin using ribonucleic acid interference disrupted microtubule nucleation from centrosomes during mitosis, through the mislocalization of $\gamma$-tubulin, a microtubule-nucleating protein from spindle poles. ${ }^{53}$ Further studies confirmed the role of pericentrin in microtubule nucleation because recruitment of $\gamma$-tubulin by Plk1 needs the presence of pericentrin. ${ }^{54}$

In prometaphase, a group of proteins including Aurora kinase B (AURKB), microtubule-associated serine/threonine kinase-like (MASTL), and Mps-1/TTK are involved in the processes of spindle assembly and chromosome attachment. ${ }^{55}$ Moreover, during the next stage, metaphase, AURKB, Mps-1/TTK, and Nek are some of the proteins in charge of chromosome alignment and the SAC, which monitors the attachment of spindle microtubules to the kinetochores of chromosomes. ${ }^{34} \mathrm{We}$ will discuss these proteins in more detail now.

AURKB functions in the regulation of corrections of kinetochore-microtubule attachments during spindle assembly ensuring normal mitotic progression. Specifically, this protein corrects the destabilization of the interactions of kinetochore-microtubules through a mechanism involving phosphorylation of EB2. ${ }^{56}$

One of the main roles of the MASTL involves the regulation of the mitotic phase progression by the inactivation of the tumor suppressor protein phosphatase $2 \mathrm{~A} / \mathrm{B} 55 \mathrm{~d}$, as the mechanism for maintaining the activity of cyclin $\mathrm{B} / \mathrm{Cdk} 1 .{ }^{57}$ In the same line, Malumbres discovered that a mouse model with conditional knockout of MASTL has mitosis with normal kinetics, however after nuclear envelope breakdown MASTL absence causes mitotic collapse. ${ }^{58}$

Mps-1/TTK was identified in budding yeast as a kinase required for spindle pole body duplication. ${ }^{59}$ TTK has its maximal activity and expression during mitosis, where it promotes efficient chromosome alignment. ${ }^{60}$ Another major function of TTK is that it supports the function of the SAC through the recruitment of mitotic arrest deficient 1 (Mad1) and mitotic arrest deficient $2(\mathrm{Mad} 2)$ to the unattached kinetochores. ${ }^{61-64}$ Also, Plk1 phosphorylates TTK to fully activate the SAC. ${ }^{65}$ Albeit that the mechanism is unknown, deregulation of TTK in breast cancer cells results in CA. ${ }^{66}$

Budding uninhibited by benzimidazoles 1 (Bub1) and BubR1 are serine/threonine kinases that stabilize kinetochore-microtubules and also play a major role in the attachment and alignment of the chromosome. ${ }^{67} \mathrm{Bub} 1$ is required for the localization of SAC components to kinetochores, and recently it was discovered that Bub1 binds to the transforming growth factor- $\beta$ receptor which is involved in development of abnormal cell growth, epithelial-mesenchymal transition, and tumors. ${ }^{68,69}$

Nek 2 is a protein required for centrosome disjunction and the formation of a bipolar mitotic spindle. ${ }^{70}$ It exerts centrosome disjunction by phosphorylating c-Nap and rootletin. ${ }^{71,72}$ Nek2 exerts its role in the SAC through the interaction with Hec-1 (a protein involved in spindle checkpoint signaling), also known as Ndc80, and also with Mad1. ${ }^{73-76} \mathrm{Nek} 2$ is particularly abundant in cells during the G2-M phase. Abnormal Nek2 expression induces CA in breast cancer cells, and alters microtubule dynamics that can trigger tissue reorganization during tumorigenesis. ${ }^{34,77-80}$ Thus, Nek2 is critical for microtubule organization and ensures fidelity of chromosome segregation during mitosis. 


\section{Overview of structural and functional aberrations in the centrosome associated with abnormal cell proliferation}

Structural or functional centrosomal disturbances are known to cause abnormal cell proliferation leading to the formation of tumors. The proposed role of centrosomes in cancer disease arose more than a century ago with the German zoologist, Theodor Boveri (1862-1915) and his chromosome theory of cancer. ${ }^{81}$ After observing the consequences of abnormal mitoses in sea urchin eggs, Boveri further suggested in his monograph that "malignant tumors might result of a certain abnormal condition of the chromosomes, which may arise from multipolar mitosis". After this theory, many discoveries and interests have risen in this research area ${ }^{82}$

Centrosome defects in cancer can be classified into two main categories based on structural or functional alterations. Among the structural aberrations that can be found in centrosomes are changes in shape or structure (amorphous, stringlike structures, ring-like, atypical filaments, and corkscrew); size (usually seen as large patchy aggregates, but may range from tiny flecks); number (three or more per cell); position (diffuse patchy cytoplasmic staining, scattered, or clustered), and/or composition (inappropriate proteins levels, inappropriate phosphorylation, and absence of centrioles). Regarding functionality, centrosome defects can have consequences leading to abnormal microtubule nucleation and disorganized mitotic spindles, leading to abnormal segregation of chromosomes and aneuploidy. ${ }^{18,47}$

Several studies in this area have established abnormal centrosomes as potential players in cancer disease. A crucial study by Pihan et al analyzed various primary tumors derived from breast, lung, prostate, colon, and brain, as well as metastatic tumors from breast, lung, and colon to examine centrosomal abnormalities. High magnification of malignant tumors showed centrosome structural abnormalities in size (3- to 10-fold increase in centrosomal diameter), shape, number (several pericentrin foci indicating the presence of supernumerary centrosomes), and diffuse patchy cytoplasmic pericentrin staining in tumor tissues when compared to nontumoral cells from the adjacent normal tissue. ${ }^{47}$ Centrosomal abnormalities are not only exclusive to solid tumors, but also are present in leukemia and lymphomas. Evidence of that was obtained by the group of Fonseca, demonstrating that abnormal patterns of string-like structures and ring-like patterns are predominant in multiple myeloma and that CA was observed in all stages of gammopathies. ${ }^{82}$ Also, they noticed an increase in the percentage of plasma cells with
CA that progressed from monoclonal gammopathy of undetermined significance to multiple myeloma. Another study analyzing cells derived from tissues of 33 patients diagnosed with hepatocellular carcinoma showed various centrosome abnormal patterns, including abnormal shape and size and also supernumerary centrosomes. ${ }^{83}$ Despite the fact that the frequency of centrosomal abnormalities found was lower when compared with other studies previously done, 30 of the 33 tissues showed abnormal centrosomes from which the non-diploid tumors were in their majority associated with defects in $\mathrm{p} 53$. A recent study by Garcez et al ${ }^{84}$ showed that neurons silenced for centromere protein $\mathrm{J}$ (Cenpj), a protein expressed in mitotic cells in developing brains, showed decreased centrosome size in Cenpj-silenced cortical progenitor cells. Garcez et al also counted centrioles in centringreen fluorescent protein (GFP) in co-electroporated cells finding an increase in single centrioles in Cenpj-silenced cells as well as asymmetric spindles with reduced fluorescence for $\alpha$-tubulin that was associated with a smaller centrosome at one pole. ${ }^{84}$ All of these studies have provided vast evidence correlating centrosome abnormalities to cancer. In Table 1 we summarize additional studies of different types of tumors associated with centrosome disturbances with the protein(s) involved, the corresponding histologic characteristic, or other related information.

\section{Potential as an anticancer target}

Centrosomes play an important role in the control of cell cycle, a process deregulated in many cancers. ${ }^{93}$ The many associated proteins found in the centrosome orchestrate the control of microtubule nucleation and organization for the proper progression of cell cycle. Abnormal function of these proteins leads to numerical centrosome abnormalities, referred to as CA.

The hypothesis of CA as a cause in the development of cancer has long been suggested..${ }^{94} \mathrm{~A}$ vast majority of evidence supports the presence of aberrant centrosomes in several types of tumors, and its implication as the major mechanism driving the generation of multipolar mitoses, chromosome instability (CIN), and aneuploidy. ${ }^{18,95}$ This fact makes the centrosome a promising therapy to target cancer.

Several oncogenes and tumor suppressors are known to localize within centrosomes, and their malfunction triggers centrosome abnormalities. ${ }^{19}$ Two of the most studied centrosomal kinases with oncogenic properties are AURKA and AURKB. AURKA dysfunction is related to CA and CIN and it is highly overexpressed in colon, pancreatic, head and neck, bladder, ovary, and breast cancers. ${ }^{96-102}$ Moreover, 
Table I Correlation of centrosome aberrations in different types of tumors

\begin{tabular}{|c|c|c|c|c|}
\hline Cancer type & $\mathbf{N}$ & $\begin{array}{l}\text { Co-expression } \\
\text { of cancer marker }\end{array}$ & Histology/other information & References \\
\hline Breast & 362 & Pericentrin, Ki67 & $\begin{array}{l}\text { Higher CA in higher stage and grade tumors; higher CA and ploidy } \\
\text { or acentriolar in triple negative and HER2 tumors }\end{array}$ & Denu et $\mathrm{a}^{85}$ \\
\hline Prostate & 99 & $\Uparrow$ Nek2 & Correlated with a Gleason score $>8$, metastasis, PSA failure, and OS & Zeng et $\mathrm{a}^{86}$ \\
\hline Gastric & 186 & $\Uparrow \mathrm{TACC} 3$ & Extracapsular extension and tumor relapse, shortened OS and DFS & Yun et $\left.a\right|^{87}$ \\
\hline $\begin{array}{l}\text { Bladder } \\
\text { (NMIBC) }\end{array}$ & 78 & Pericentrin & CA was correlated with disease progression & Miyachika et al ${ }^{88}$ \\
\hline Breast & 31 & $\Uparrow \mathrm{Plk} 4 \Downarrow \mathrm{KLFI} 4$ & Not provided & Fan et $\mathrm{al}^{89}$ \\
\hline Colon & 15 & & & \\
\hline Esophageal & 78 & $\Uparrow$ Aurora $\mathrm{A}$ & Better prognosis regarding clinical response to chemoradiation & Tamotsu et a $\left.\right|^{90}$ \\
\hline Pancreas & 133 & PP4C & $\begin{array}{l}\text { Correlated with distal metastasis and poor survival in patients in } \\
\text { stage II }\end{array}$ & Weng et $\mathrm{al}^{91}$ \\
\hline Ovarian & $\begin{array}{l}43 \text { high grade } \\
\text { SC } 37 \text { STIC }\end{array}$ & CCNEI & Higher CA in SC compared with STIC & Kuhn et $\mathrm{a}^{92}$ \\
\hline
\end{tabular}

Abbreviations: DFS, disease free survival; N, sample size; NMIBC, non-muscle invasive bladder cancer; OS, overall survival; PSA, prostate-specific antigen; SC, serous carcinoma; STIC, serous tubal intraepithelial carcinoma; CA, centrosome amplification.

AURKB is overexpressed in non-small cell lung cancer (NSCLC), glioblastoma, prostate, and breast cancers. ${ }^{102,103}$

Plk1 is part of the serine/threonine kinases related to the cell cycle regulation and is activated by AURKA. Besides the role of Plk1 in cell cycle, this protein is also involved in anti-apoptotic and invasiveness regulation. ${ }^{55}$ This protein represents an important potential target in cancer due to the promising results obtained using inhibitors that have been used in clinical trials. ${ }^{104}$

Cdks are central regulators of the centrosome cycle and represent potential target proteins, broadly studied in cancer. ${ }^{19,105}$ There have been $\sim 30$ small-molecule inhibitors developed against $\mathrm{Cdks},{ }^{106}$ and one third of them have been used in clinical trials studies. ${ }^{107}$ The G1 phase Cdks, Cdk2 and Cdk4, regulate the centrosome cycle by phosphorylating centrosome kinases such as NPM and TTK, $, 26,35,108,109$ and by phosphorylation of $\mathrm{Rb}$ leading to the transcriptional activation of the E2F transcription factors. In turn, the E2Fs regulate the centrosome cycle..$^{31,110}$ Our laboratory has shown that the Cdks mediate CA in breast cancer cells and mammary epithelial cells by regulating the E2F transcription factors, which regulate the expression of several centrosome regulators, including Plk4 and Nek2. ${ }^{77-79}$ Thus, controlling CA by the use of small-molecule inhibitors against the G1 Cdks is a potential avenue for suppressing CA in cancer, as long as the $\mathrm{Rb}$ pathway is functional. ${ }^{111}$

Tubulin seems to be another important target, as this protein functions during cellular growth, division, and migration. This target has been demonstrated to be successful due to the effects of taxanes (paclitaxel and docetaxel) and vinca alkaloids (vinblastine, vincristine, and vinorelbine). ${ }^{112}$ Paclitaxel, vinblastine, and vincristine are well-known compounds clinically used for targeting tubulin as their mechanisms of action. ${ }^{113,114}$ There are two mechanisms of action for targeting microtubules: 1) microtubule-stabilizing agents, which bind to the tubulin-binding site of paclitaxel, and 2) microtubule destabilizing-agents, which bind to the tubulin vinblastine or colchicine site. ${ }^{115}$ In addition, a new series of acridinones have been recently developed against microtubule-assembly inhibitors showing reduced cell migration, inhibition of tubulin polymerization, and arrest in the G2-M phase. ${ }^{112}$

Thus, there are many promising inhibitors against associated centrosome proteins and many of these drugs/compounds are being tested in preclinical and clinical models. The last topic of this review will summarize some compounds developed that have been obtaining successful results in targeting centrosomal regulatory proteins.

\section{Drug development activity}

Cancer disease is characterized by the loss of normal cell cycle control. As the centrosome plays a major role in the regulation of cell cycle control, it has become an attractive target for cancer treatment. Interestingly, a variety of compounds have been used against proteins involved in the regulation of different cell cycle points including drugs targeting the microtubule dynamics, Plks, Cdks, and AURK inhibitors. Targets against microtubule dynamics including taxanes (paclitaxel and docetaxel) and vinca alkaloids (vinblastine, vincristine, and vinorelbine) have been found to be successful in the treatment of different cancers, including breast, ovarian, and lung. However, they have shown adverse effects on organelles and protein trafficking in non-dividing cells, indicating that these compounds do not distinguish between malignant and non-malignant cells. ${ }^{116} \mathrm{~A}$ recent study discovered four acridinones compounds that seem to be promising therapies against cancer due to their potent anticancer effects with 
selective toxicity against MDA-MB-231 and DU-145, causing G2-M arrest, inhibition of cell migration, and apoptosis. ${ }^{12}$

Targeting the Plks showed interesting results in preclinical cancer studies, but with minimal efficacy in clinical trials. The compound BI 2536 (a potent small-molecule inhibitor of mammalian Plk1) has been tested in phase I/II for the treatment of various cancers with partial or complete response, but with neutropenia and leukopenia present in 30\%-40\% of patients. This treatment showed response in $9 \%$ of acute myeloid leukemia (AML) patients and partial response in $4 \%$ of NSCLC patients. Other drugs such as GSK461364A and TAK-960 have been retired from clinical trials due to the toxicity or lack of effectivity. However, BI 6727 resulted in being efficacious in the treatment of AML as $12 \%$ of patients obtained total remission. Moreover, administration of a combination of BI 6727 with cytaribine increased the response with $31 \%$ total remission, compared to cytarabine alone with $13 \%$. $^{117}$

Inhibitors against $\mathrm{Cdks}$ have been used as cancer targets as they mediate the arrest in G1-S and G2-M phases. Flavopiridol, the first $\mathrm{Cdk}$ inhibitor used in clinical trials, inhibits in vitro cell growth by targeting Cdk2, Cdk4, and Cdk6 in G1-S or G2-M phases of the cell cycle. ${ }^{118,119}$ In addition, flavopiridol induces apoptosis pathways through caspases. ${ }^{120}$ Specifically, flavopiridol has been effective in the treatment of AML and chronic lymphocytic leukemia (CLL). ${ }^{55}$ Dinaciclib, a novel inhibitor of Cdks 1, 2, 5, and 9, is superior to flavopiridol in AML and CLL because patients have much less myelosuppression; however, it has not been successful for the treatment of solid tumors. ${ }^{55}$ Among the newest anti-Cdks agents to be used in clinical trials are PD0332991 (palbociclib), LEE011 (ribociclib), and LY2835219 (abemaciclib), which are Cdk4/6 inhibitors. ${ }^{121-123}$ The US Food and Drug Administration has recently approved the use of palbociclib combination with letrozole for the treatment of breast tumors expressing estrogen receptor and human epidermal receptor 2 in their advanced stages.

Another important protein target against centrosome for cancer therapy is the AURKs. More than 30 AURK inhibitors have been developed and used in clinical studies. ${ }^{124}$ For example, the inhibitor MLN8237 (alisertib), which targets AURKA, showed promising efficacy in several solid tumors, however, the same efficacy was not observed in AML patients. ${ }^{125}$ Also, Alisertib showed effective results in $13 \%$ of non-Hodgkin's lymphoma and CLL patients, and a $50 \%$ effectivity rate in patients with T-cell lymphoma. ${ }^{126}$ AZD1152 (barasertib) is a selective inhibitor of AURKB and has been effective in AML patients with an overall response rate of $25 \%$, but with no effective results in patients with solid tumors. In addition, AURKB/AURKC kinase inhibitor
GSK1070916A is actually being tested in patients with solid tumors and phase I has been completed.

Recently, other inhibitors have been approved for phase I clinical trials, ${ }^{55}$ including those against Plk4 (CFI400945) ${ }^{127-129}$ and TTK (BAY1161909). ${ }^{130}$ A preclinical trial of BAY1161909 reports abrogation of the SAC, moderate suppression of tumorigenesis, and more significant inhibition of tumor growth when combined with paclitaxel. ${ }^{130}$ Phase I clinical trial (clinical trials.gov) using BAY1161909 along with paclitaxel is currently under recruitment phase. On the other hand, treatment of cells with CFI-400945 resulted in defective centriole duplication, cell death, and tumor suppression in xenograft mouse models. ${ }^{128}$

There are many ongoing studies to test the efficacy of targeting different centrosomal proteins in order to achieve cancer control. The continuing development of these compounds shows the magnitude of the centrosome as an organelle that can be targeted to control different types of cancer.

\section{Conclusion}

The discovery of the centrosome more than a century ago represented a major achievement in cancer research. The centrosome has become a main character in the regulation of the cell cycle, and as a result, an important target for cancer therapy, because loss of control of the cell cycle represents a hallmark in cancer disease, and the centrosome cycle is in part regulated by the cell cycle machinery. Abnormal centrosomes including CA lead to CIN, and aneuploidy, which are commonly found in malignant tumors. Many drugs/ compounds targeting centrosomal proteins including Cdks, Aurora kinase family, and tubulin among others have been developed and used for the treatment of different cancers, while others are currently being tested in clinical trials or remain to be elucidated. Thus, this tiny organelle has arisen as a good candidate for cancer treatment.

\section{Acknowledgments}

We want to thank The Puerto Rico Science, Technology and Research Trust and Ponce Medical Foundation Inc. under the cooperative agreement 2016-00026, the U54 PSM-MCC Partnership Grant \#U54CA163071, and the PRCTRC grant support under Award Number 2U54MD007587.

\section{Disclosure}

The authors report no conflicts of interest in this work.

\section{References}

1. Wunderlich V. JMM — past and present. Chromosomes and cancer: Theodor Boveri's predictions 100 years later. J Mol Med (Berl). 2002;80(9):545-548. 
2. Bettencourt-Dias M, Glover DM. Centrosome biogenesis and function: centrosomics brings new understanding. Nat Rev Mol Cell Biol. 2007;8(6):451-463

3. Paintrand M, Moudjou M, Delacroix H, Bornens M. Centrosome organization and centriole architecture: their sensitivity to divalent cations. J Struct Biol. 1992;108(2):107-128.

4. Bornens M. Centrosome composition and microtubule anchoring mechanisms. Curr Opin Cell Biol. 2002;14(1):25-34.

5. Gogendeau D, Guichard P, Tassin AM. Purification of centrosomes from mammalian cell lines. Methods Cell Biol. 2015;129: 171-189.

6. Piel M, Meyer P, Khodjakov A, Rieder CL, Bornens M. The respective contributions of the mother and daughter centrioles to centrosome activity and behavior in vertebrate cells. J Cell Biol. 2000;149(2): 317-330.

7. Shukla A, Kong D, Sharma M, Magidson V, Loncarek J. Plk1 relieves centriole block to reduplication by promoting daughter centriole maturation. Nat Commun. 2015;6:8077.

8. Basto R, Lau J, Vinogradova T, Gardiol A, Woods CG, Khodjakov A, Raff JW. Flies without centrioles. Cell. 2006;125(7):1375-1386.

9. Azimzadeh J, Wong ML, Downhour DM, Sanchez Alvarado A, Marshall WF. Centrosome loss in the evolution of planarians. Science. 2012;335(6067):461-463.

10. Bettencourt-Dias M, Hildebrandt F, Pellman D, Woods G, Godinho SA. Centrosomes and cilia in human disease. Trends Genet. 2011;27(8): 307-315.

11. Mennella V, Keszthelyi B, McDonald KL, et al. Subdiffraction-resolution fluorescence microscopy reveals a domain of the centrosome critical for pericentriolar material organization. Nat Cell Biol. 2012; 14(11):1159-1168.

12. Andersen JS, Wilkinson CJ, Mayor T, Mortensen P, Nigg EA, Mann M. Proteomic characterization of the human centrosome by protein correlation profiling. Nature. 2003;426(6966):570-574.

13. Alves-Cruzeiro JM, Nogales-Cadenas R, Pascual-Montano AD CentrosomeDB: a new generation of the centrosomal proteins database for Human and Drosophila melanogaster. Nucleic Acids Res. 2014;42(Database issue):D430-D436.

14. Lawo S, Hasegan M, Gupta GD, Pelletier L. Subdiffraction imaging of centrosomes reveals higher-order organizational features of pericentriolar material. Nat Cell Biol. 2012;14(11):1148-1158.

15. Moritz M, Agard DA. Gamma-tubulin complexes and microtubule nucleation. Curr Opin Struct Biol. 2001;11(2):174-181.

16. Sluder G. Centrosomes and the cell cycle. J Cell Sci Suppl. 1989; 12:253-275.

17. Chretien D, Buendia B, Fuller SD, Karsenti E. Reconstruction of the centrosome cycle from cryoelectron micrographs. J Struct Biol. 1997;120(2):117-133.

18. Chan JY. A clinical overview of centrosome amplification in human cancers. Int J Biol Sci. 2011;7(8):1122-1144.

19. Fukasawa K. Oncogenes and tumour suppressors take on centrosomes. Nat Rev Cancer. 2007;7(12):911-924.

20. Duensing S. Analysis of centrosomes in human cancer. Methods Cell Biol. 2015;129:51-60.

21. Steere N, Wagner M, Beishir S, et al. Centrosome amplification in CHO and DT40 cells by inactivation of cyclin-dependent kinases. Cytoskeleton (Hoboken). 2011;68(8):446-458

22. Adon AM, Zeng X, Harrison MK, Sannem S, Kiyokawa H, Kaldis P, Saavedra HI. Cdk2 and Cdk4 regulate the centrosome cycle and are critical mediators of centrosome amplification in p53-null cells. Mol Cell Biol. 2010;30(3):694-710.

23. Tokuyama Y, Horn HF, Kawamura K, Tarapore P, Fukasawa K. Specific phosphorylation of nucleophosmin on $\operatorname{Thr}(199)$ by cyclin-dependent kinase 2-cyclin $\mathrm{E}$ and its role in centrosome duplication. J Biol Chem. 2001;276(24):21529-21537.

24. Tarapore P, Horn HF, Tokuyama Y, Fukasawa K. Direct regulation of the centrosome duplication cycle by the p53-p21Waf1/Cip1 pathway. Oncogene. 2001;20(25):3173-3184.
25. Mussman JG, Horn HF, Carroll PE, Okuda M, Tarapore P, Donehower LA, Fukasawa K. Synergistic induction of centrosome hyperamplification by loss of p53 and cyclin E overexpression. Oncogene. 2000;19(13):1635-1646.

26. Okuda M, Horn HF, Tarapore P, et al. Nucleophosmin/B23 is a target of CDK2/cyclin E in centrosome duplication. Cell. 2000;103(1):127-140.

27. Hinchcliffe EH, Li C, Thompson EA, Maller JL, Sluder G. Requirement of Cdk2-cyclin $\mathrm{E}$ activity for repeated centrosome reproduction in Xenopus egg extracts. Science. 1999;283(5403):851-854.

28. Lacey KR, Jackson PK, Stearns T. Cyclin-dependent kinase control of centrosome duplication. Proc Natl Acad Sci USA. 1999;96(6):2817-2822.

29. Matsumoto Y, Hayashi K, Nishida E. Cyclin-dependent kinase 2 (Cdk2) is required for centrosome duplication in mammalian cells. Curr Biol. 1999;9(8):429-432.

30. Spruck CH, Won KA, Reed SI. Deregulated cyclin E induces chromosome instability. Nature. 1999;401(6750):297-300.

31. Meraldi P, Lukas J, Fry AM, Bartek J, Nigg EA. Centrosome duplication in mammalian somatic cells requires E2F and Cdk2-cyclin A. Nat Cell Biol. 1999;1(2):88-93.

32. Harrison MK, Adon AM, Saavedra HI. The G1 phase Cdks regulate the centrosome cycle and mediate oncogene-dependent centrosome amplification. Cell Div. 2011;6:2.

33. Nigg EA, Raff JW. Centrioles, centrosomes, and cilia in health and disease. Cell. 2009;139(4):663-678.

34. Marina M, Saavedra HI. Nek2 and Plk4: prognostic markers, drivers of breast tumorigenesis and drug resistance. Front Biosci (Landmark Ed). 2014;19:352-365.

35. Fisk HA, Winey M. The mouse Mps1p-like kinase regulates centrosome duplication. Cell. 2001;106(1):95-104

36. Mikule K, Delaval B, Kaldis P, Jurcyzk A, Hergert P, Doxsey S. Loss of centrosome integrity induces p38-p53-p21-dependent G1-S arrest. Nat Cell Biol. 2007;9(2):160-170.

37. Picard A, Karsenti E, Dabauvalle MC, Doree M. Release of mature starfish oocytes from interphase arrest by microinjection of human centrosomes. Nature. 1987;327(6118):170-172.

38. Perez-Mongiovi D, Beckhelling C, Chang P, Ford CC, Houliston E. Nuclei and microtubule asters stimulate maturation/M phase promoting factor (MPF) activation in Xenopus eggs and egg cytoplasmic extracts. J Cell Biol. 2000;150(5):963-974.

39. Hirota T, Kunitoku N, Sasayama T, et al. Aurora-A and an interacting activator, the LIM protein Ajuba, are required for mitotic commitment in human cells. Cell. 2003;114(5):585-598.

40. Kramer A, Mailand N, Lukas C, et al. Centrosome-associated Chk1 prevents premature activation of cyclin-B-Cdk1 kinase. Nat Cell Biol. 2004;6(9):884-891.

41. Lane HA, Nigg EA. Antibody microinjection reveals an essential role for human polo-like kinase 1 (Plk1) in the functional maturation of mitotic centrosomes. J Cell Biol. 1996;135(6 Pt 2):1701-1713.

42. Mardin BR, Agircan FG, Lange C, Schiebel E. Plk1 controls the Nek2A-PP1 gamma antagonism in centrosome disjunction. Curr Biol. 2011;21(13):1145-1151.

43. Spankuch-Schmitt B, Bereiter-Hahn J, Kaufmann M, Strebhardt K. Effect of RNA silencing of polo-like kinase-1 (PLK1) on apoptosis and spindle formation in human cancer cells. J Natl Cancer Inst 2002;94(24):1863-1877.

44. Kellogg DR. Centrosomes. Organizing cytoplasmic events. Nature. 1989;340(6229):99-100.

45. Meadows JC, Millar JB. Sharpening the anaphase switch. Biochem Soc Trans. 2015;43(1):19-22.

46. Brinkley BR. Managing the centrosome numbers game: from chaos to stability in cancer cell division. Trends Cell Biol. 2001;11(1):18-21.

47. Pihan GA, Purohit A, Wallace J, Knecht H, Woda B, Quesenberry P, Doxsey SJ. Centrosome defects and genetic instability in malignant tumors. Cancer Res. 1998;58(17):3974-3985.

48. Zimmerman WC, Sillibourne J, Rosa J, Doxsey SJ. Mitosis-specific anchoring of gamma tubulin complexes by pericentrin controls spindle organization and mitotic entry. Mol Biol Cell. 2004;15(8):3642-3657. 
49. Oakley CE, Oakley BR. Identification of gamma-tubulin, a new member of the tubulin superfamily encoded by mipA gene of Aspergillus nidulans. Nature. 1989;338(6217):662-664.

50. Stearns T, Evans L, Kirschner M. Gamma-tubulin is a highly conserved component of the centrosome. Cell. 1991;65(5):825-836.

51. Zheng Y, Jung MK, Oakley BR. Gamma-tubulin is present in Drosophila melanogaster and Homo sapiens and is associated with the centrosome. Cell. 1991;65(5):817-823.

52. Stearns T, Kirschner M. In vitro reconstitution of centrosome assembly and function: the central role of gamma-tubulin. Cell. 1994;76(4): 623-637.

53. Zimmerman S, Daga RR, Chang F. Intra-nuclear microtubules and a mitotic spindle orientation checkpoint. Nat Cell Biol. 2004;6(12):1245-1246.

54. Haren L, Stearns T, Luders J. Plk1-dependent recruitment of gammatubulin complexes to mitotic centrosomes involves multiple PCM components. PLoS One. 2009;4(6):e5976.

55. Dominguez-Brauer C, Thu KL, Mason JM, Blaser H, Bray MR, Mak TW. Targeting mitosis in cancer: emerging strategies. Mol Cell. 2015;60(4):524-536.

56. Iimori M, Watanabe S, Kiyonari S, et al. Phosphorylation of EB2 by Aurora B and CDK1 ensures mitotic progression and genome stability. Nat Commun. 2016;7:11117.

57. Burgess A, Vigneron S, Brioudes E, Labbe JC, Lorca T, Castro A. Loss of human Greatwall results in G2 arrest and multiple mitotic defects due to deregulation of the cyclin B-Cdc2/PP2A balance. Proc Natl Acad Sci USA. 2010;107(28):12564-12569.

58. Alvarez-Fernandez M, Sanchez-Martinez R, Sanz-Castillo B, et al. Greatwall is essential to prevent mitotic collapse after nuclear envelope breakdown in mammals. Proc Natl Acad Sci U S A. 2013; 110(43):17374-17379.

59. Liu X, Winey M. The MPS1 family of protein kinases. Annu Rev Biochem. 2012;81:561-585.

60. Dou Z, Liu X, Wang W, et al. Dynamic localization of Mps1 kinase to kinetochores is essential for accurate spindle microtubule attachment. Proc Natl Acad Sci U S A. 2015;112(33):E4546-E4555.

61. Martin-Lluesma S, Stucke VM, Nigg EA. Role of Hec1 in spindle checkpoint signaling and kinetochore recruitment of Mad1/Mad2. Science. 2002;297(5590):2267-2270.

62. Vigneron S, Prieto S, Bernis C, Labbe JC, Castro A, Lorca T. Kinetochore localization of spindle checkpoint proteins: who controls whom? Mol Biol Cell. 2004;15(10):4584-4596.

63. Heinrich S, Windecker H, Hustedt N, Hauf S. Mph1 kinetochore localization is crucial and upstream in the hierarchy of spindle assembly checkpoint protein recruitment to kinetochores. J Cell Sci. 2012;125(Pt 20):4720-4727.

64. Sliedrecht T, Zhang C, Shokat KM, Kops GJ. Chemical genetic inhibition of Mps1 in stable human cell lines reveals novel aspects of Mps1 function in mitosis. PLoS One. 2010;5(4):e10251.

65. von Schubert C, Cubizolles F, Bracher JM, Sliedrecht T, Kops GJ, Nigg EA. Plk1 and Mps1 cooperatively regulate the spindle assembly checkpoint in human cells. Cell Rep. 2015;12(1):66-78.

66. Lee MY, Marina M, King JL, Saavedra HI. Differential expression of centrosome regulators in Her2+ breast cancer cells versus nontumorigenic MCF10A cells. Cell Div. 2014;9:3.

67. Meraldi P, Sorger PK. A dual role for Bub1 in the spindle checkpoint and chromosome congression. EMBO J. 2005;24(8):1621-1633.

68. Nyati S, Schinske-Sebolt K, Pitchiaya S, et al. The kinase activity of the Ser/Thr kinase BUB1 promotes TGF-beta signaling. Sci Signal. 2015;8(358):ra1.

69. Gonzalez DM, Medici D. Signaling mechanisms of the epithelialmesenchymal transition. Sci Signal. 2014;7(344):re8.

70. Faragher AJ, Fry AM. Nek2A kinase stimulates centrosome disjunction and is required for formation of bipolar mitotic spindles. Molecular biology of the cell. 2003;14(7):2876-2889.

71. Hardy T, Lee M, Hames RS, et al. Multisite phosphorylation of C-Nap1 releases it from Cep135 to trigger centrosome disjunction. J Cell Sci. 2014;127(Pt 11):2493-2506.
72. Fry AM, Mayor T, Meraldi P, StierhofYD, Tanaka K, Nigg EA. C-Nap1, a novel centrosomal coiled-coil protein and candidate substrate of the cell cycle-regulated protein kinase Nek2. J Cell Biol. 1998; 141(7):1563-1574.

73. Chen Y, Riley DJ, Zheng L, Chen PL, Lee WH. Phosphorylation of the mitotic regulator protein $\mathrm{Hec} 1$ by Nek2 kinase is essential for faithful chromosome segregation. J Biol Chem. 2002;277(51):49408-49416.

74. Du J, Cai X, Yao J, et al. The mitotic checkpoint kinase NEK2A regulates kinetochore microtubule attachment stability. Oncogene. 2008;27(29):4107-4114.

75. Lou Y, Yao J, Zereshki A, et al. NEK2A interacts with MAD1 and possibly functions as a novel integrator of the spindle checkpoint signaling. J Biol Chem. 2004;279(19):20049-20057.

76. Wei R, Ngo B, Wu G, Lee WH. Phosphorylation of the Ndc 80 complex protein, HEC1, by Nek2 kinase modulates chromosome alignment and signaling of the spindle assembly checkpoint. Mol Biol Cell. 2011;22(19):3584-3594.

77. Lee M, Oprea-Ilies G, Saavedra HI. Silencing of E2F3 suppresses tumor growth of Her2+ breast cancer cells by restricting mitosis. Oncotarget. 2015.

78. Lee MY, Moreno CS, Saavedra HI. The E2F activators signal and maintain centrosome amplification in breast cancer cells. Mol Cell Biol. 2014;34(14):2581-2599.

79. Harrison Pitner MK, Saavedra HI. Cdk4 and nek2 signal binucleation and centrosome amplification in a her2+ breast cancer model. PLoS One. 2013;8(6):e65971.

80. Zeng X, Shaikh FY, Harrison MK, et al. The Ras oncogene signals centrosome amplification in mammary epithelial cells through cyclin D1/Cdk4 and Nek2. Oncogene. 2010;29(36):5103-5112.

81. McKusick VA. Marcella O'Grady Boveri (1865-1950) and the chromosome theory of cancer. J Med Genet. 1985;22(6):431-440.

82. Chng WJ, Ahmann GJ, Henderson K, et al. Clinical implication of centrosome amplification in plasma cell neoplasm. Blood. 2006;107(9): 3669-3675.

83. Nakajima T, Moriguchi M, Mitsumoto Y, et al. Centrosome aberration accompanied with p53 mutation can induce genetic instability in hepatocellular carcinoma. Mod Pathol. 2004;17(6):722-727.

84. Garcez PP, Diaz-Alonso J, Crespo-Enriquez I, Castro D, Bell D, Guillemot F. Cenpj/CPAP regulates progenitor divisions and neuronal migration in the cerebral cortex downstream of Ascl1. Nat Commun. 2015;6:6474

85. Denu RA, Zasadil LM, Kanugh C, Laffin J, Weaver BA, Burkard ME. Centrosome amplification induces high grade features and is prognostic of worse outcomes in breast cancer. BMC Cancer. 2016;16:47.

86. Zeng YR, Han ZD, Wang C, et al. Overexpression of NIMA-related kinase 2 is associated with progression and poor prognosis of prostate cancer. BMC Urol. 2015;15:90.

87. Yun M, Rong J, Lin ZR, et al. High expression of transforming acidic coiled coil-containing protein 3 strongly correlates with aggressive characteristics and poor prognosis of gastric cancer. Oncol Rep. 2015; 34(3):1397-1405.

88. Miyachika Y, Yamamoto Y, Matsumoto H, et al. Centrosome amplification in bladder washing cytology specimens is a useful prognostic biomarker for non-muscle invasive bladder cancer. Cancer Genet. 2013; 206(1-2):12-18.

89. Fan G, Sun L, Shan P, et al. Loss of KLF14 triggers centrosome amplification and tumorigenesis. Nat Commun. 2015;6:8450.

90. Tamotsu K, Okumura H, Uchikado Y, et al. Correlation of Aurora-A expression with the effect of chemoradiation therapy on esophageal squamous cell carcinoma. BMC Cancer. 2015;15:323.

91. Weng S, Wang H, Chen W, et al. Overexpression of protein phosphatase 4 correlates with poor prognosis in patients with stage II pancreatic ductal adenocarcinoma. Cancer Epidemiol Biomarkers Prev. 2012;21(8):1336-1343.

92. Kuhn E, Wang TL, Doberstein K, et al. CCNE1 amplification and centrosome number abnormality in serous tubal intraepithelial carcinoma: further evidence supporting its role as a precursor of ovarian high-grade serous carcinoma. Mod Pathol. 2016;29(10):1254-1261. 
93. Sivonova MK, Vilckova M, Kliment J, et al. Association of p53 and p21 polymorphisms with prostate cancer. Biomed Rep. 2015;3(5): 707-714.

94. Boveri T. Concerning the origin of malignant tumours by Theodor Boveri. Translated and annotated by Henry Harris. J Cell Sci. 2008; 121(Suppl 1):1-84.

95. Milunovic-Jevtic A, Mooney P, Sulerud T, Bisht J, Gatlin JC. Centrosomal clustering contributes to chromosomal instability and cancer. Curr Opin Biotechnol. 2016;40:113-118.

96. Zhang H, Chen X, Jin Y, Liu B, Zhou L. Overexpression of AuroraA promotes laryngeal cancer progression by enhancing invasive ability and chromosomal instability. Eur Arch Otorhinolaryngol. 2012;269(2):607-614.

97. Bischoff JR, Anderson L, Zhu Y, et al. A homologue of Drosophila aurora kinase is oncogenic and amplified in human colorectal cancers. EMBO J. 1998;17(11):3052-3065.

98. Zhou H, Kuang J, Zhong L, et al. Tumour amplified kinase STK15/ BTAK induces centrosome amplification, aneuploidy and transformation. Nat Genet. 1998;20(2):189-193.

99. Tanner MM, Grenman S, Koul A, et al. Frequent amplification of chromosomal region 20q12-q13 in ovarian cancer. Clin Cancer Res. 2000; 6(5):1833-1839.

100. Watanabe T, Imoto I, Katahira T, et al. Differentially regulated genes as putative targets of amplifications at $20 \mathrm{q}$ in ovarian cancers. Jpn J Cancer Res. 2002;93(10):1114-1122.

101. Rojanala S, Han H, Munoz RM, Browne W, Nagle R, Von Hoff DD, Bearss DJ. The mitotic serine threonine kinase, Aurora-2, is a potential target for drug development in human pancreatic cancer. Mol Cancer Ther. 2004;3(4):451-457.

102. Malumbres M. Physiological relevance of cell cycle kinases. Physiol Rev. 2011;91(3):973-1007.

103. Lens SM, Voest EE, Medema RH. Shared and separate functions of polo-like kinases and aurora kinases in cancer. Nat Rev Cancer. 2010;10(12):825-841.

104. Yim H. Current clinical trials with polo-like kinase 1 inhibitors in solid tumors. Anticancer Drugs. 2013;24(10):999-1006.

105. Harrison MK, Adon AM, Saavedra HI. The G1 phase Cdks regulate the centrosome cycle and mediate oncogene-dependent centrosome amplification. Cell Div. 2010;6:2.

106. Malumbres M, Barbacid M. Cell cycle, CDKs and cancer: a changing paradigm. Nat Rev Cancer. 2009;9(3):153-166.

107. Cicenas J, Kalyan K, Sorokinas A, Jatulyte A, Valiunas D, Kaupinis A, Valius M. Highlights of the latest advances in research on CDK inhibitors. Cancers (Basel). 2014;6(4):2224-2242.

108. Adon AM, Zeng X, Harrison MK, Sannem S, Kiyokawa H, Kaldis P, Saavedra HI. Cdk2 and Cdk4 regulate the centrosome cycle and are critical mediators of centrosome amplification in p53-null cells. $\mathrm{Mol}$ Cell Biol. 2010;30(3):694-710.

109. Kasbek C, Yang CH, Yusof AM, Chapman HM, Winey M, Fisk HA. Preventing the degradation of mps 1 at centrosomes is sufficient to cause centrosome reduplication in human cells. Mol Biol Cell. 2007; 18(11):4457-4469.

110. Saavedra HI, Maiti B, Timmers C, Altura R, Tokuyama Y, Fukasawa K, Leone $\mathrm{G}$. Inactivation of E2F3 results in centrosome amplification. Cancer Cell. 2003;3(4):333-346.

111. Bosco EE, Knudsen ES. RB in breast cancer: at the crossroads of tumorigenesis and treatment. Cell Cycle. 2007;6(6):667-671.

112. Magalhaes LG, Marques FB, da Fonseca MB, Rogerio KR, Graebin CS, Andricopulo AD. Discovery of a series of acridinones as mechanismbased tubulin assembly inhibitors with anticancer activity. PLoS One. 2016;11(8):e0160842.
113. Schiff PB, Fant J, Horwitz SB. Promotion of microtubule assembly in vitro by taxol. Nature. 1979;277(5698):665-667.

114. Himes RH. Interactions of the catharanthus (Vinca) alkaloids with tubulin and microtubules. Pharmacol Ther. 1991;51(2):257-267.

115. Xi J, Zhu X, Feng Y, et al. Development of a novel class of tubulin inhibitors with promising anticancer activities. Mol Cancer Res. 2013; 11(8):856-864.

116. Weaver BA, Cleveland DW. Does aneuploidy cause cancer? Curr Opin Cell Biol. 2006;18(6):658-667.

117. Gjertsen BT, Schoffski P. Discovery and development of the Polo-like kinase inhibitor volasertib in cancer therapy. Leukemia. 2015;29(1):11-19.

118. Carlson BA, Dubay MM, Sausville EA, Brizuela L, Worland PJ. Flavopiridol induces G1 arrest with inhibition of cyclin-dependent kinase (CDK) 2 and CDK4 in human breast carcinoma cells. Cancer Res. 1996;56(13):2973-2978.

119. Losiewicz MD, Carlson BA, Kaur G, Sausville EA, Worland PJ. Potent inhibition of CDC2 kinase activity by the flavonoid L86-8275. Biochem Biophys Res Commun. 1994;201(2):589-595.

120. Cobanoglu G, Turacli ID, Ozkan AC, Ekmekci A. Flavopiridol's antiproliferative effects in glioblastoma multiforme. J Cancer Res Ther. 2016;12(2):811-817.

121. Fry DW, Harvey PJ, Keller PR, et al. Specific inhibition of cyclindependent kinase 4/6 by PD 0332991 and associated antitumor activity in human tumor xenografts. Mol Cancer Ther. 2004;3(11):1427-1438.

122. Gelbert LM, Cai S, Lin X, et al. Preclinical characterization of the CDK4/6 inhibitor LY2835219: in-vivo cell cycle-dependent/independent anti-tumor activities alone/in combination with gemcitabine. Invest New Drugs. 2014;32(5):825-837.

123. Zhang YX, Sicinska E, Czaplinski JT, et al. Antiproliferative effects of CDK4/6 inhibition in CDK4-amplified human liposarcoma in vitro and in vivo. Mol Cancer Ther. 2014;13(9):2184-2193.

124. Kollareddy M, Zheleva D, Dzubak P, Brahmkshatriya PS, Lepsik M, Hajduch M. Aurora kinase inhibitors: progress towards the clinic. Invest New Drugs. 2012;30(6):2411-2432.

125. Goldberg SL, Fenaux P, Craig MD, et al. An exploratory phase 2 study of investigational Aurora A kinase inhibitor alisertib (MLN8237) in acute myelogenous leukemia and myelodysplastic syndromes. Leuk Res Rep. 2014;3(2):58-61.

126. Kelly KR, Shea TC, Goy A, et al. Phase I study of MLN8237--investigational Aurora A kinase inhibitor--in relapsed/refractory multiple myeloma, non-Hodgkin lymphoma and chronic lymphocytic leukemia. Invest New Drugs. 2014;32(3):489-499.

127. Sampson PB, Liu Y, Forrest B, et al. The Discovery of Polo-Like Kinase 4 Inhibitors: Identification of (1R,2S)-2-(3-((E)-4-(((cis)2,6-Dimethylmorpholino)methyl)styryl)-1H-indazol-6-yl )5'-methoxyspiro[cyclopropane-1,3'-indolin]-2'-one (CFI-400945) as a potent, orally active antitumor agent. J Med Chem. 2015;58(1): 147-169

128. Mason JM, Lin DC, Wei X, et al. Functional characterization of CFI400945, a Polo-like kinase 4 inhibitor, as a potential anticancer agent. Cancer Cell. 2014;26(2):163-176.

129. Laufer R, Forrest B, Li SW, et al. The discovery of PLK4 inhibitors: (E)-3-((1H-Indazol-6-yl)methylene)indolin-2-ones as novel antiproliferative agents. J Med Chem. 2013;56(15):6069-6087.

130. Wengner AM, Siemeister G, Koppitz M, et al. Novel Mps1 kinase inhibitors with potent antitumor activity. Mol Cancer Ther. 2016;15(4): 583-592.

131. Boveri T. 1902 Über mehrpolige Mitosen als Mittel zur Analyse des Zellkerns. Verhandl Phys Med Ges Würzburg. 1902;35:67-90. German. 


\section{Publish your work in this journal}

Biologics: Targets and Therapy is an international, peer-reviewed journal focusing on the patho-physiological rationale for and clinical application of Biologic agents in the management of autoimmune diseases, cancers or other pathologies where a molecular target can be identified. This journal is indexed on PubMed Central, EMBase, and Scopus.
The manuscript management system is completely online and includes a very quick and fair peer-review system, which is all easy to use Visit http://www.dovepress.com/testimonials.php to read real quotes from published authors.

Submit your manuscript here: https://www.dovepress.com/biologics-targets-and-therapy-journal 